\title{
Article Risk Analysis of One-Way Road Tunnel Tube Used for
Bi-Directional Traffic under Fire Scenarios
}

\author{
Ciro Caliendo *(D), Isidoro Russo (D) and Gianluca Genovese (D) \\ Department of Civil Engineering, University of Salerno, Fisciano, 84084 Salerno, Italy; isrusso@unisa.it (I.R.); \\ ggenovese@unisa.it (G.G.) \\ * Correspondence: ccaliendo@unisa.it; Tel.: +39-8996-4140
}

Citation: Caliendo, C.; Russo, I.; Genovese, G. Risk Analysis of One-Way Road Tunnel Tube Used for Bi-Directional Traffic under Fire Scenarios. Appl. Sci. 2021, 11, 3198. https://doi.org/10.3390/app11073198

Academic Editors: Luís Picado Santos and Igal Shohet

Received: 11 February 2021

Accepted: 30 March 2021

Published: 2 April 2021

Publisher's Note: MDPI stays neutral with regard to jurisdictional claims in published maps and institutional affiliations.

Copyright: (c) 2021 by the authors. Licensee MDPI, Basel, Switzerland. This article is an open access article distributed under the terms and conditions of the Creative Commons Attribution (CC BY) license (https:// creativecommons.org/licenses/by/ $4.0 /)$.

\begin{abstract}
We have set up a Computational Fluid Dynamics (CFD) modeling, and performed a user evacuation model, for evaluating the risk level in one-way road tunnel tube when used for bidirectional traffic in particular circumstances. The simulations were carried out by considering both peak-hour traffic volumes during the day and off-peak hours overnight. The investigated one-way tube is ventilated by natural ventilation only, and has a length of less than $1000 \mathrm{~m}$. With reference to the worst environmental conditions, which are downstream of the fire due to the direction of natural ventilation, the consequences on escaping users, caused by different types of burning vehicles located in various longitudinal positions along the tube, are shown. The results prove the positive effects on environmental conditions (in terms of temperature, visibility distance, $\mathrm{CO}$ and $\mathrm{CO}_{2}$ concentration) along the user evacuation path when the tube is used for bi-directional traffic at night rather than daytime. Only for the case of $100 \mathrm{MW}$ fire and in the proximity of the exit portal, the last escaping user might be affected by a visibility distance and $\mathrm{CO}$ concentration exceeding the threshold values. In this special case, countermeasures for reducing smoke concentration or emergency services at the portals should be provided. However, the quantitative risk analysis, based on a probabilistic approach, showed that the F-N curve of the tube when used for bi-directional traffic with reference to the night always lies below that of the daytime, and the reduction in the risk level is between 80 and $100 \%$ for the night traffic compared to daytime one. It is to be focused on the fact that our modeling may represent a reference in investigating the effects of hourly traffic volumes on the risk level in tunnels and may help decisionmakers in understanding when to temporarily close a tube for maintenance, repair, or rehabilitation activities and use the adjacent tube for bi-directional traffic.
\end{abstract}

Keywords: quantitative risk analysis; computational fluid dynamics; peak-hour traffic volumes; one-way road tunnel tube; bi-directional traffic; F-N curves

\section{Introduction}

Road tunnels, as part of a transport infrastructure, play an essential role in supporting the mobility of goods and people. For providing useful effects in terms of social and economic benefits, it is extremely important to keep tunnels available for traffic as much as possible. Maintenance, repair, and/or rehabilitation works within a tunnel usually make more difficult the transit of motor vehicles, and sometimes the tunnel might also be temporarily closed for safety reasons. In these cases, the consequent functionality loss of road infrastructure might be recovered by using an alternative itinerary or temporary reorganizing - for example if a twin-tube tunnel is present-the traffic flow by using a tube originally characterized by unidirectional traffic for bi-directional traffic, when the adjacent tube is closed.

However, a one-way tunnel tube when used for traffic in two driving directions under particular circumstances might present much more dangerous conditions for users than when it is used for one driving direction, since more serious head-on-collisions, in terms of injuries and/or fatalities, might be expected. In addition, worse environmental 
conditions in the event of fire within the tube (e.g., temperatures, smoke concentration, visibility distance, and toxic substances) might also be expected along the user escape path downstream of the fire. In fact, due to the ventilation direction (mechanical or natural) within the originally unidirectional tube, the hot airflow is generally pushed towards people who are in the zone downstream of the fire, and that having left their own motor vehicles in the queue to run away from the burning vehicle in the direction of a safe place (emergency exits or portal). It is to be stressed, in the case of unidirectional traffic tube, that users downstream of the fire can, instead, escape with their own vehicles towards the exit portal without any significant risk.

Indeed, the mentioned problem of additional risks in a one-way tunnel tube when is used for bi-directional traffic in the event of a fire has hitherto been hardly investigated. Moreover, the impacts on increased risk due to the traffic variations are not yet clearly understood. The unit of measure for traffic generally used in a risk analysis is the Annual Average Daily Traffic (AADT), defined as the total traffic volume in one year divided by the number of days in one year. However, the AADT does not reflect the fact that traffic can vary seasonally, by day of the week (e.g., weekdays or weekends), and by hour of the day. This means that the estimation of the number of persons exposed to risk within a tunnel in the event of fire, which is concatenated with the mentioned traffic variations, might not be sufficiently precise. Traffic volumes referring to an interval of time shorter than one day are more appropriate to represent, other than the service level of tunnel, more exactly the number of users who risk their own health due to a tunnel fire. In this respect, peak-hour traffic volumes during the day should be more especially implemented in risk analysis. In addition, hourly traffic volumes at night should be also considered in order to make appropriate comparisons between the different risk levels (i.e., night versus day).

The mentioned topic of discussion in the risk analysis of tunnels (i.e., the use of oneway tube for bi-directional traffic during both daily peak-hours and overnight in the event of a fire) indicates a lack of knowledge that is needed to be filled, which is the scope of the present paper. In the light of the above considerations, this study aims to investigate in greater depth the effects of a fire on the people evacuation process from an originally one-way tunnel tube that is used temporarily for bi-directional traffic. Thus, the present paper may provide additional knowledge in the field of tunnel safety engineering, as well as to make proposals to minimize the risk level in a tube when it is necessary to close the adjacent tube for maintenance, repair, and/or rehabilitation activities.

To do so, a fluid dynamic model was developed, the resolution of which was made by using the Fire Dynamics Simulator (FDS) version 6.7.3 [1,2] with its evacuation module Evac version 2.5.2 [3]. The investigated tunnel is an existing tunnel located along an Italian motorway. It is a twin-tube tunnel with a cross-connection between the two tubes (as one emergency exit) in the middle of the tunnel length. Each tube, in ordinary functionality conditions, is used only for one driving direction. Each tube is not equipped with mechanical ventilation system, which is not mandatory for one-way tube with length less than $1000 \mathrm{~m}$ [4]. Therefore, only natural ventilation caused by vehicles in motion (piston effect) is considered. To achieve the purpose of the present paper, it is assumed that a tube is used for bi-directional traffic when the adjacent tube is closed for given activities.

The paper is organized as follows: the next section contains a literature review concerning certain studies based on the use of fluid dynamics modeling for assessing the risk level in unidirectional and/or bi-directional road tunnels in the event of fire. Then the developed model is presented and implemented. Subsequently, the results related to the use of the single tube for bi-directional traffic under peak-hour traffic volumes during the day and overnight are presented and discussed on, and appropriate comparisons are made between night and day. Finally, conclusions and addresses for additional research are made. 


\section{Literature Review}

Several studies have applied Computational Fluid Dynamics (CFD) models for assessing the risk level of unidirectional and/or bi-directional road tunnels in the event of fire.

Modic [5] carried out fire simulations in a tunnel with unidirectional traffic (one way-one tunnel), under the hypothesis that one of the two parallel tunnels presents an incident and the other one is without any incident. The two tunnels are linked by crossconnections every $400 \mathrm{~m}$ for escape. Due to the ventilation direction (i.e., natural caused by the traffic-induced piston effect and/or longitudinal mechanical), they found that the worst conditions occurred downstream of the fire.

$\mathrm{Li}$ and Chow [6] simulated tunnel fires by using CFD in order to investigate the effects of different ventilation systems. The authors found that under unidirectional traffic the airflow velocity is able to guarantee safety conditions upstream of the fire; however, it might not be true in bi-directional traffic operations since people evacuate in both directions.

Hu et al. [7] performed full-scale tunnel fire tests in order to validate FDS simulations. The tunnel investigated is equipped by mechanical ventilation, and a cross-passage in the middle of the tunnel connecting the two adjacent tubes. The temperatures predicted by FDS matched the experimental results and more hazardous conditions were measured downstream of the fire.

Bari and Naser [8], by using the CFD software FLUENT 6.0, simulated a fire in a unidirectional tunnel with axial jet fans. They found that most of the smoke was pushed downstream of the fire, without any significant consequence since the vehicles downstream of the fire escaped from the exit portal, while the smoke dispersed upstream of the fire within a certain distance from the burning vehicle could put users at great risk.

Yang et al. [9], by using CFD modeling combined with an evacuation model, evaluated the safety level in one of the longest road tunnels in China equipped with cross-passages between the tubes. They found that it is unsafe to evacuate downstream of the fire due to the direction and more especially the high velocity of the ventilation, therefore measures should be in place to direct user evacuation process upstream of the fire.

Betta et al. [10] applied a CFD model for investigating the efficiency of an alternative jet fan in a one-way road tunnel. Two scenarios without traffic and with traffic jam were considered in the fire simulations. They showed that the proposed alternative solution was equivalent to the traditional one in terms of safety level, and that the worst environmental conditions occurred with the presence of vehicular traffic.

Babapoor et al. [11], by using the FDS code, investigated the effectiveness of two ventilation systems (natural or forced). They found that only the natural ventilation was not able to guarantee safe evacuation, while the forced ventilation ensured a safe route for escaping upstream of the fire.

Caliendo et al. [12-14], by using the ANSYS-CFX code, assessed the effects of a fire located in different positions along a bi-directional road tunnel equipped with longitudinal mechanical ventilation both with and without traffic. More severe fire-induced threats were found (due to the direction of ventilation) downstream of the fire and with the presence of queued vehicle, which acted as obstacles, and when the fire was located in the middle of the tunnel length. Moreover, other fire sources were investigated: safety conditions, along the evacuation path downstream of the fire, were found up to $5 \mathrm{~min}, 6.6 \mathrm{~min}$, and $8 \mathrm{~min}$ after the fire started in the event of petrol tanker, HGV, and bus fire, respectively. This meant that the tunnel users to be safe should leave the tunnel within $5 \mathrm{~min}$ from the fire start. This might be done by equipping the tunnel with additional safety measures such as illuminated signs for people evacuation, and the presence of traffic lights at the entrance portal to close the tunnel as soon as possible in the event of fire.

Lin et al. [15] carried out CFD simulations in a road tunnel equipped with semitransversal smoke control system. The aim was to investigate the effects of the obstruction of vehicles queued behind the fire source. They found that with the high vehicular block- 
ages in the tunnel, the proposed smoke control system might not be effective in the event of a real fire.

Caliendo et al. [16], by using the ANSYS CFX+STEPS tools and on the basis of traffic flow expressed in terms of the Annual Average Daily Traffic (AADT), showed the effects of fire-induced threats on users, during their escape process downstream of the fire, for different positions of burning vehicles in a bi-directional road tunnel equipped with longitudinal mechanical ventilation. They also showed the advantages of providing the tunnel with emergency exits, and an optimal distance between the emergency exits was also identified.

Truchot et al. [17] conducted several CFD simulations to compare two different approaches for assessing the risk level in a one-way road tunnel. While in the first approach the walking speed of tunnel users is based on the smoke opacity, in the second one it depends on the exposure to both heat and toxic gases. However, the comparison showed only minor differences in the case investigated under the aspect of people safety.

Caliendo et al. [18], by applying the FDS+Evac codes for a unidirectional road tunnel tube equipped with natural ventilation only and implementing the peak-hour traffic volume (VHP) during the day, evaluated the effects on escaping users upstream of the fire due to different types of burning vehicles located at different longitudinal positions along the one-way tube. They showed that the mechanical ventilation is not required in this case. However, it is to be stressed that they did not investigate the use of the one-way tube for bi-directional traffic.

A. Król and M. Król [19], after examining the formation of traffic congestion due to an accident by using a traffic simulation tool, simulated the fire development in a one-way tunnel by means of FDS and modelled the evacuation process with the PATHFINDER software. They found that the number of trapped users upstream of the fire varies with traffic (i.e., it is higher for congested traffic because of the higher number of users exposed to risk). The risk increased with the traffic volume, and the factor that most affected the safety of users was smoke rather than temperature.

From the above chronological literature review, one may note that the mentioned studies have mainly focused on the evaluation of the effects of fires in unidirectional or bi-directional road tunnels under usual traffic directions. However, the effects of a fire on people evacuation process when a one-way tube is used for bi-directional traffic in fire scenarios, for example if the adjacent tube is temporarily closed for specified activities, do not appear to have hitherto been sufficiently investigated during both day and night. This represents a lack of knowledge that is needed to be investigated in greater depth, which is the intent of the present paper. It is to be stressed that in our previous papers, we did not investigate a one-way tunnel used for bi-directional traffic under particular circumstances, as well as equipped with natural ventilation only. The increase of the risk level in one-way tunnel tube used for bi-directional traffic in the event of fire-when the adjacent tube is closed for maintenance, repair, and rehabilitation activities-has not been hitherto quantified in function of the traffic volume that can vary by hour of the day (e.g., night versus day). This is a gap of knowledge that is needed to be filled, which is the scope of the present paper.

\section{Materials and Methods}

\subsection{Tunnel Tube Characteristics}

The investigated road tunnel tube is existing and is located along an Italian motorway. It is flat and straight, with a length of $850 \mathrm{~m}$, having two lanes, and without emergency lanes. The emergency exits are the cross-connection between the two tunnel tubes, and the two portals of the tube. Since there is not a mechanical ventilation system, the ventilation within the tube is natural and is due to the piston effect of vehicles in motion. In this respect, it is to be remembered that, in the case of unidirectional traffic flow, the natural ventilation was simulated by applying a positive pressure difference of $5 \mathrm{~Pa}$ between the entrance portal (portal A) and the exit one (portal B) [18]. 
When the tube is, instead, used for bi-directional traffic, a reduced effect of the natural ventilation is assumed for taking into account the two opposite driving directions. In particular, a positive pressure difference of only 0.5 Pa between portal A and portal B was assumed in the present paper. This might be justified by the fact that the speed of vehicles that do not change tube (i.e., direction from portal A to B) is a bit higher than the speed of vehicles in the opposite direction that are forced to slow down to change carriageway and then to accelerate within the investigated tube (i.e., direction from portal B to A). The tunnel concrete walls have a thickness of $0.4 \mathrm{~m}$. The concrete thermal conductivity is assumed to be equal to $1.67 \mathrm{~W} / \mathrm{m} / \mathrm{K}$, the value of the specific heat is $0.94 \mathrm{~kJ} / \mathrm{kg} / \mathrm{K}$, the density is $2585 \mathrm{~kg} / \mathrm{m}^{3}$, and finally the emissivity is 0.9 . Specifically, the thickness of $0.4 \mathrm{~m}$ is related to the walls of the existing tunnel; while the properties of concrete, given the lack of accurate data, were taken from the literature [20] and are referred to an ordinary concrete, which is similar to that used in the investigated tunnel.

\subsection{Traffic}

The peak traffic flow, expressed in terms of hourly volume, was found to be, according to the traffic data provided by the Tunnel Management Agency (TMA), in six 1-h time periods (i.e., 7:00-8:00 a.m., 8:00-9:00 a.m., 1:00-2:00 p.m., 2:00-3:00 p.m., 5:00-6:00 p.m., and 6:00-7:00 p.m.). However, since the closure of the adjacent tube during the day might create very high levels of congestion in the investigated tube due to its use for bi-directional traffic, we assumed in the risk analysis that the hourly volume in each of the aforementioned six hours were equal to the bi-directional capacity of the tube (i.e., 3200 vehicles/hour for the two lanes). Lower traffic volumes were found, instead, overnight (i.e., from 10:00 p.m. and 6:00 a.m. (8 h)): a bi-directional traffic of 400 vehicles/h was assumed. The percentage of Heavy Goods Vehicles (HGVs), which was provided by the TMA, is equal to $25 \%$.

\subsection{Description of Fire Scenarios}

In the present study, four fire scenarios involving two cars, a bus, and two different types of HGVs are considered. Each fire source is assumed to be positioned in five different locations from portal A (i.e., the entrance portal for the case of unidirectional traffic). The geometric characteristics of the burning vehicles, the corresponding Heat Release Rates (HRRs), the fire growth curves vs time, and the yields of combustion products have already been reported and discussed in the previous paper of the authors [18]; therefore, they are not presented here in order to save space.

\subsection{Research Framework}

The present paper is set in the context of research on the evacuation process of people from road tunnels in the event of fire scenarios but extends the state-of-the-art by means of the development of a computational fluid dynamics modeling for assessing the risk level in function of hourly traffic volumes during both the day and night, and for performing a probabilistic approach aimed at quantifying the expected potential number of fatalities. Therefore, this research aims to serve, given the lacuna of knowledge, as a possible reference for tunnel management agencies, and to further our experience in the field of fire safety engineering. The methodology applied is briefly showed in Figure 1. 


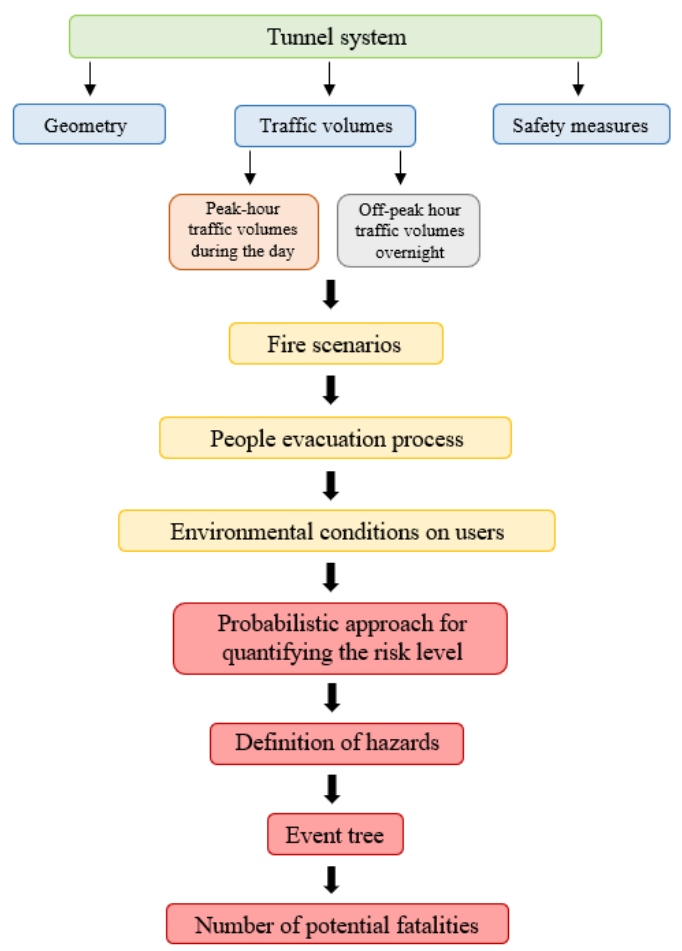

Figure 1. Flow chart of the methodology.

\section{CFD Modeling}

The finite volume method was used in the Computational Fluid Dynamics (CFD) modeling to solve, within each cell in which the tunnel tube volume was discretized, the main governing equations (i.e., continuity, momentum, and energy equations), which are coupled with sub-models describing the physical phenomena (i.e., combustion, turbulence, and thermal radiation). The accuracy of CFD modeling results depends more especially on the fire scenario, physical models used, and mesh fineness. In our study, we used the FDS version 6.7.3, which is developed by the US. National Institute of Standards and Technology (NIST). It represents an open source CFD modeling, widely employed to simulate tunnel fire scenarios. The aforementioned physical phenomena implemented in FDS are, instead, discussed in depth in the FDS user's guide [1]. However, the main input data of FDS regard: tunnel geometry, position of emergency exits, location and geometry of burning vehicle as well as its HRR, pressure difference between portals, yields of combustion products, number and distance between the vehicles queued (computed by using hourly traffic volume at the time of fire).

It is to be stressed that we preliminarily validated the FDS code by making a comparison between the simulation results with the experimental data of temperatures reported in Xue et al. [21]; an error of no more than $5 \%$ proved a good level of conformity.

After validating the FDS code, a grid sensitivity analysis was performed to define an appropriate mesh resolution. The results of this analysis, which are reported more in details in Caliendo et al. [18], showed that a cell size smaller than $0.4 \mathrm{~m}$ did not provide substantial differences in temperature predictions. Therefore, the tunnel tube was divided into cubic cells of $0.4 \mathrm{~m}$ side. A total number of 1,095,255 cells was employed in our study.

\section{Evacuation Modeling}

\subsection{Egress Simulation Model}

Egress simulations were carried out by means of Evac [3], which is the evacuation module of the FDS. The model allows users to move in a two-dimensional space and to take into account the fact that their behavior (i.e., the walking speed and/or the choice of emergency exit) might be affected by the environmental conditions (e.g., the concentration 
of toxic substances) within the tunnel caused by a burning vehicle. The input parameters of Evac, which are discussed more in detail in Caliendo et al. [18], are more especially: initial position of users at the start $(t=0)$ of fire (it is assumed to be next to his own vehicle), number of occupants in each vehicle queued ( 2 for all vehicles), pre-movement time $(1.5 \mathrm{~min})$, walking speed $(0.7 \mathrm{~m} / \mathrm{s})$, and escape direction (downstream of the fire).

It is to be remembered that Evac is not able to capture the effects of temperature and radiation on escape users; and as a result, the procedure reported in DiNenno et al. [22] was used in the present paper for this aim.

\subsection{Queue Model and Evacuation Process}

In this study, the people evacuation process was investigated by considering four types of burning vehicles (characterized by a HRR equal respectively to 8, 30, 50, and $100 \mathrm{MW}$ ) located at five different longitudinal positions from portal A $(145,280,420,570$, and $710 \mathrm{~m})$. In the case of bi-directional traffic within the tunnel tube (according to the driving direction from portal B to A) the estimation of the number of vehicles in the queue downstream of the fire is based on the following assumptions: (i) queued vehicles stop without going over the burning vehicle; (ii) vehicles queue up filling one lane; (iii) the first vehicle of the queue stops at $10 \mathrm{~m}$ from the burning vehicle; (iv) each vehicle maintains a certain distance from the preceding vehicle in the queue (i.e., $1 \mathrm{~m}$ during the daily peak-hours in which the traffic volume is equal to capacity (i.e., 1600 vehicles/hour per lane), and $10 \mathrm{~m}$ overnight due to the lowest traffic volumes (i.e., 200 vehicles/hour per lane)).

Based on the above assumptions, the number of vehicles queued downstream of the fire for each of the five locations of the burning vehicle (i.e., 145, 280, 420, 570, and $710 \mathrm{~m}$ from portal A) is equal to $98,79,59,37$, and 17 in the daily-peak hours, respectively. By assuming an average number of people present in each vehicle equal to 2 , we estimated the corresponding number of people escaping downstream of the fire: 196, 158, 118, 74, and 34. It was considered, when the burning vehicle is located at 145 or $280 \mathrm{~m}$ from portal A, that users evacuate both from the emergency exit (located in the middle of the tunnel length) and portal B. The initial position of each escaping user is assumed to be next to his own vehicle.

During each of the eight night-hours and for the aforementioned five positions of the burning vehicle, we estimated a number of vehicles queued equal to $33,33,25,16$, and 7 , respectively; and as a result the corresponding number of escaping users was found to be $66,66,50,32$, and 14 . It is to be mentioned that the number of vehicles in the queue downstream of the fire was the same for the location of the vehicle burning at both 145 and $280 \mathrm{~m}$ from the portal A. This is due to fact that after a time of $10 \mathrm{~min}$ from the fire start, the bi-directional tube is assumed to be closed to traffic by tunnel operators (i.e., overnight the maximum number of vehicles entering the bi-directional tube within $10 \mathrm{~min}$ is equal to 33 ).

Figure 2a,b show the layout of queued vehicles downstream of the burning vehicle for bi-directional traffic in both the daily peak-hours and overnight, respectively. Table 1 reports the number of people escaping from the emergency exit and portal B for the different fire locations along the tunnel.

Table 1. Number of people downstream of the fire escaping from the emergency exit and/or portal B.

\begin{tabular}{ccccc}
\hline \multirow{2}{*}{$\begin{array}{c}\text { Fire Location } \\
\text { (Distance from Portal A) }\end{array}$} & \multicolumn{4}{c}{ Number of People Escaping from: } \\
\cline { 2 - 5 } & \multicolumn{3}{c}{ Day } & \multicolumn{3}{c}{ Night } \\
\cline { 2 - 5 } & Emergency Exit & Portal B & Emergency Exit & Portal B \\
\hline $145 \mathrm{~m}$ & 102 & 94 & 45 & 21 \\
$280 \mathrm{~m}$ & 64 & 94 & 28 & 38 \\
$420 \mathrm{~m}$ & - & 118 & - & 50 \\
$570 \mathrm{~m}$ & - & 74 & - & 32 \\
$710 \mathrm{~m}$ & - & 34 & - & 14 \\
\hline
\end{tabular}




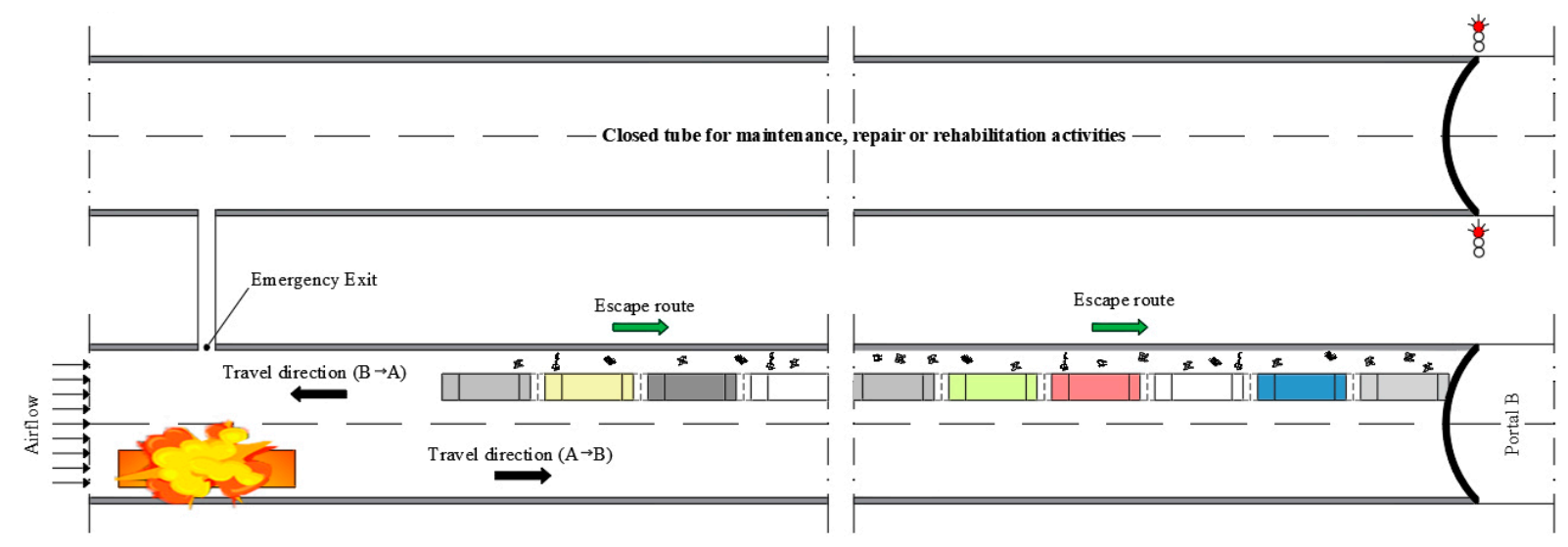

(a)

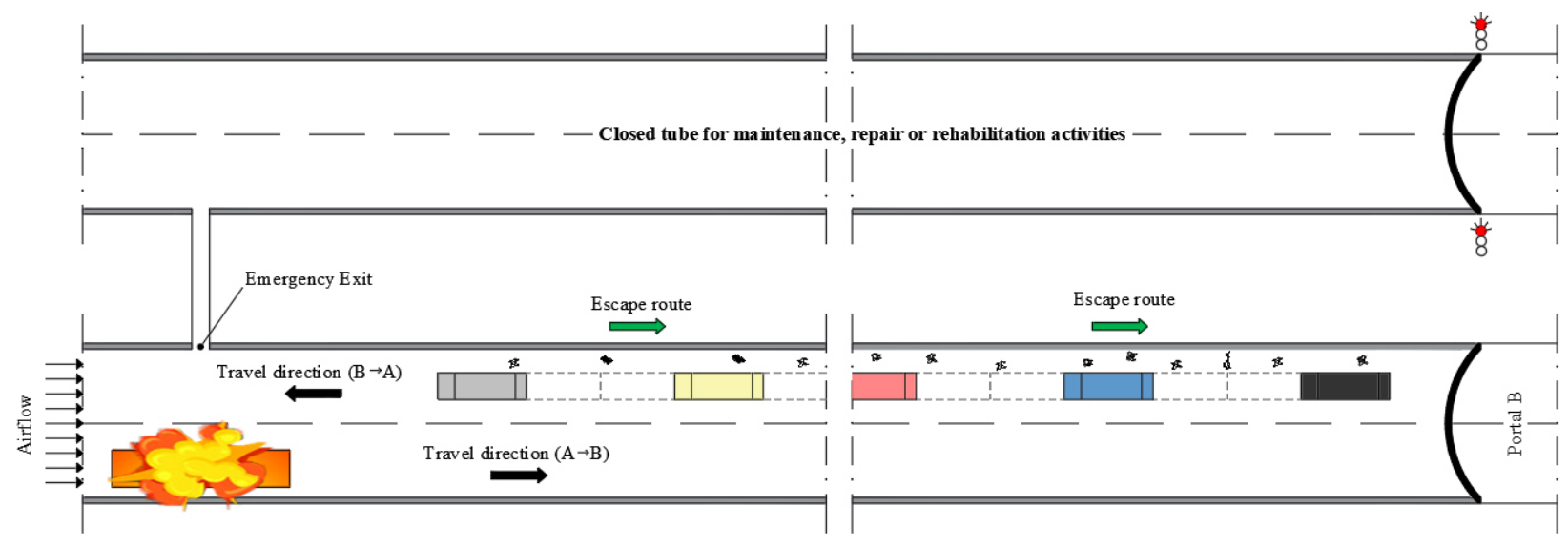

(b)

Figure 2. Layout of queued vehicles downstream of the burning vehicle during (a) daytime, and (b) overnight.

A further extension of the present paper might be that to perform a queue formation model in the event of fire in a one-way tunnel used for bi-directional traffic under emergency circumstances.

\section{Analysis of Results}

\subsection{Environmental Conditions Downstream of the Fire}

The evacuation process in the bi-directional tube, due to the natural ventilation direction, is worse for users who are downstream of the fire. In fact, users who have to walk on the sidewalk in the direction of the emergency exit and/or portal B might be exposed to higher temperatures, major smoke concentrations, and toxic substances with a greater risk of burning or suffocation. In order to assess whether users can safely evacuate from the tube in the event of a fire, the longitudinal profiles of temperature, radiative heat flux, toxic gases, and visibility distance predicted at breathing height $(2 \mathrm{~m})$ along the escape path after $10 \mathrm{~min}$ from the fire start are here reported.

The environmental conditions within the bi-directional tube were evaluated both during the day (dotted lines) and night (continuous lines). It is to be mentioned that a higher traffic volume (i.e., a major number of vehicles in the queue that act as obstacles to the spread of fire) might make the environmental conditions along the evacuation path more severe, and as a result certain differences between the day and the night are expected. Acceptability criteria were also used as a reference to verify the tenability conditions of users while evacuating along the escape path. 


\subsubsection{Longitudinal Temperature Profiles}

Figure 3 shows the longitudinal temperature profiles, downstream of the fire, in the bi-directional tube both during the day and at night after $10 \mathrm{~min}$ from the fire start, and at the breathing height $(2 \mathrm{~m})$ along the escape route when the burning vehicle is in the middle of the tube length. Figure 3 shows that the temperatures, due to hourly traffic volumes considered, are generally higher during the day than at night. With reference to a pre-movement time both of $1.5 \mathrm{~min}$ and a walking average speed of $0.7 \mathrm{~m} / \mathrm{s}$, from Figure 3 one can see the position of the last user leaving the bi-directional tube (i.e., the user nearest the burning vehicle), in direction of portal B (the emergency exit is assumed not usable in this case given the proximity of the burning vehicle) both during the day (blue user) and at night (black user). After 10 minutes from the fire start, the above-mentioned user is at a distance of $70 \mathrm{~m}$ from portal B during the night, while he/she is $58 \mathrm{~m}$ from portal B during the day. Specifically, the user corresponding to the night-time is farther from the exit portal B than during daytime. This is not surprising, since the frequency per time-unit with which the vehicles enter the bi-directional tube during the night is much lower than the day (e.g., during the night the first vehicle enters the bi-directional tube after $18 \mathrm{~s}$ from the fire start, against $2.25 \mathrm{~s}$ during the day). This means that at night, the last user who leaves the bi-directional tube in the event of fire is affected by a delay on average of $15.75 \mathrm{~s}$ before that his/her pre-movement time starts. However, Figure 3 shows that the last user evacuating from the tunnel in direction of portal B both during the night and the day is exposed to a temperature $\leq 60^{\circ} \mathrm{C}$, which is the tenability limit according to UPTUN [23].

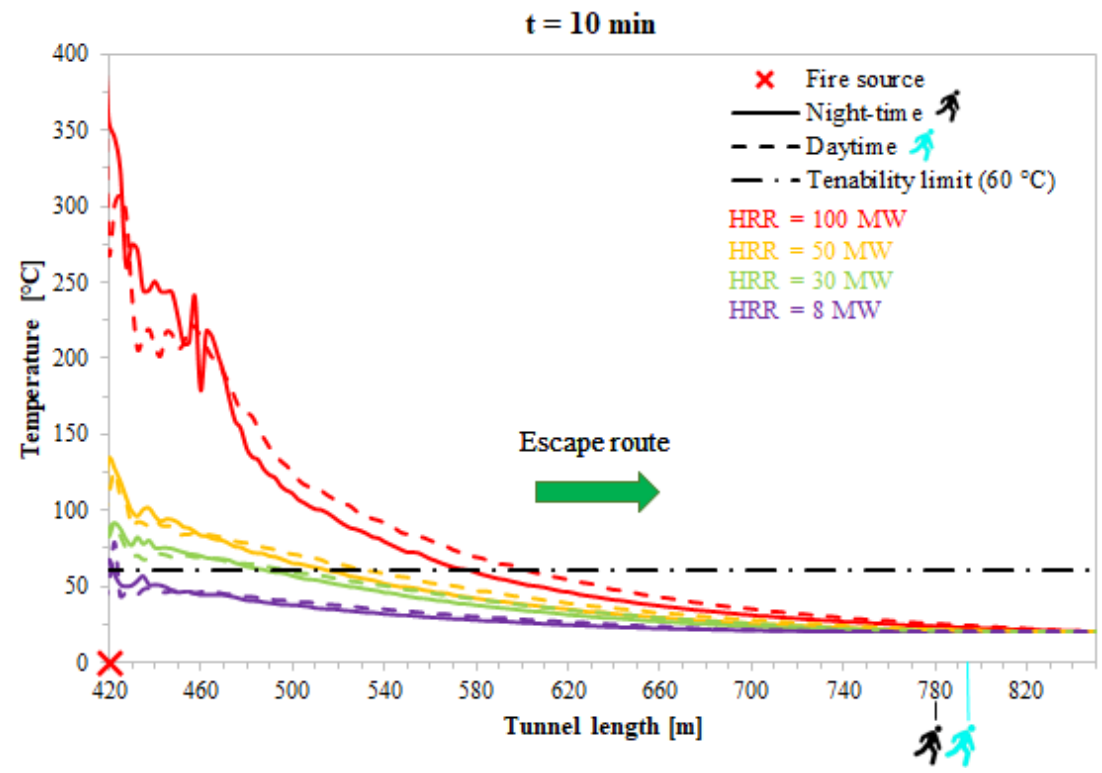

Figure 3. Longitudinal temperature profiles, downstream of the fire, in the bi-directional tube at both night and day after $10 \mathrm{~min}$ from the fire start, and at a height of $2 \mathrm{~m}$ along the escape route when the burning vehicle is in the middle of the tube length.

\subsubsection{Radiant Heat Flux}

Figure 4 shows the longitudinal radiant heat flux profiles, downstream of the fire, in the bi-directional tube at both night and day after $10 \mathrm{~min}$ from the fire start, and at a height of $2 \mathrm{~m}$ along the escape route.

This figure shows that no significant difference existed between the night and the day. From Figure 4 it is possible also to observe that the last escaping user is exposed during his evacuation process to a radiant heat flux at both night and day lower than the tenability limit $\left(2 \mathrm{~kW} / \mathrm{m}^{2}\right.$ as reported by UPTUN [23]). 


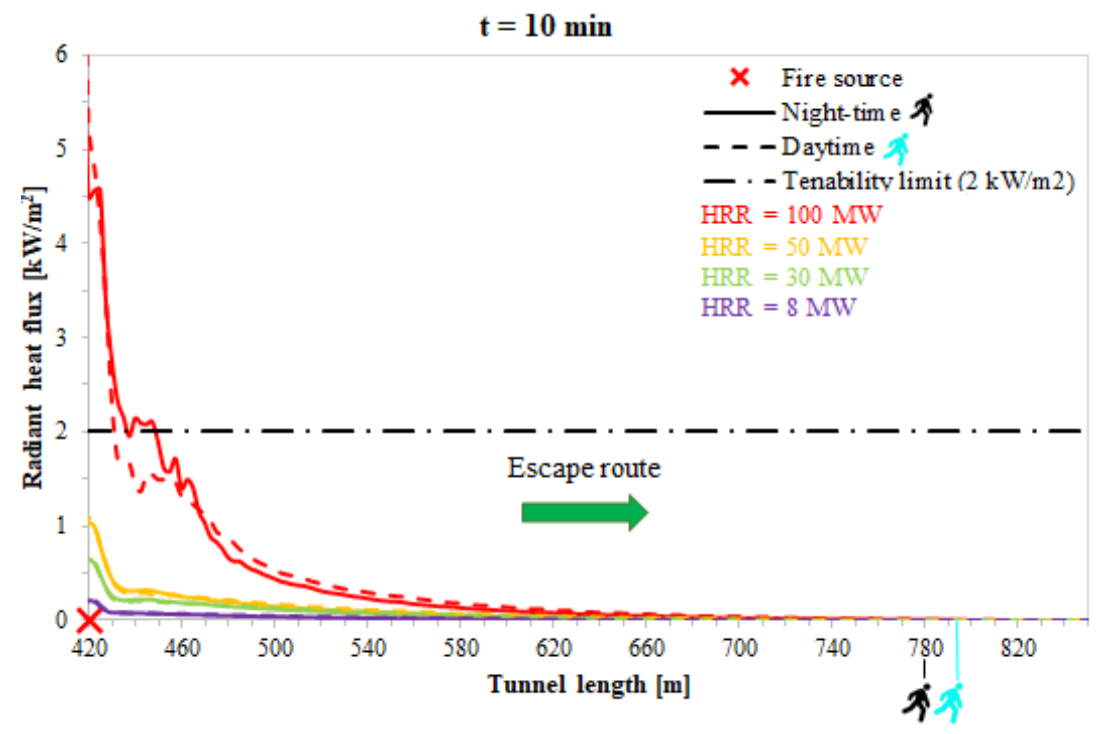

Figure 4. Longitudinal radiant heat flux profiles, downstream of the fire, in the bi-directional tube at both night and day after $10 \mathrm{~min}$ from the fire start, and at a height of $2 \mathrm{~m}$ along the escape route when the burning vehicle is in the middle of the tube length.

\subsubsection{Visibility Distance}

Figure 5 shows the longitudinal visibility distance profiles, downstream of the fire, in the bi-directional tube at both night and day after $10 \mathrm{~min}$ from the fire start, and at a height of $2 \mathrm{~m}$ along the escape route. From Figure 5, one can see that the last user evacuating from the bi-directional tube in direction of portal $\mathrm{B}$ has at night a visibility higher than day. The visibility distance is more than $10 \mathrm{~m}$ (i.e., the tenability limit according to UPTUN [23]) for 8, 30, $50 \mathrm{MW}$ fires at both night and day. In the case of $100 \mathrm{MW}$ fire, when the last escaping user is at a distance of $70 \mathrm{~m}$ and $58 \mathrm{~m}$ from portal B at night and day, respectively, the visibility distance is less than $10 \mathrm{~m}$. This means that the last user might be in unsafe conditions due to reduced visibility to discern signs for evacuating.

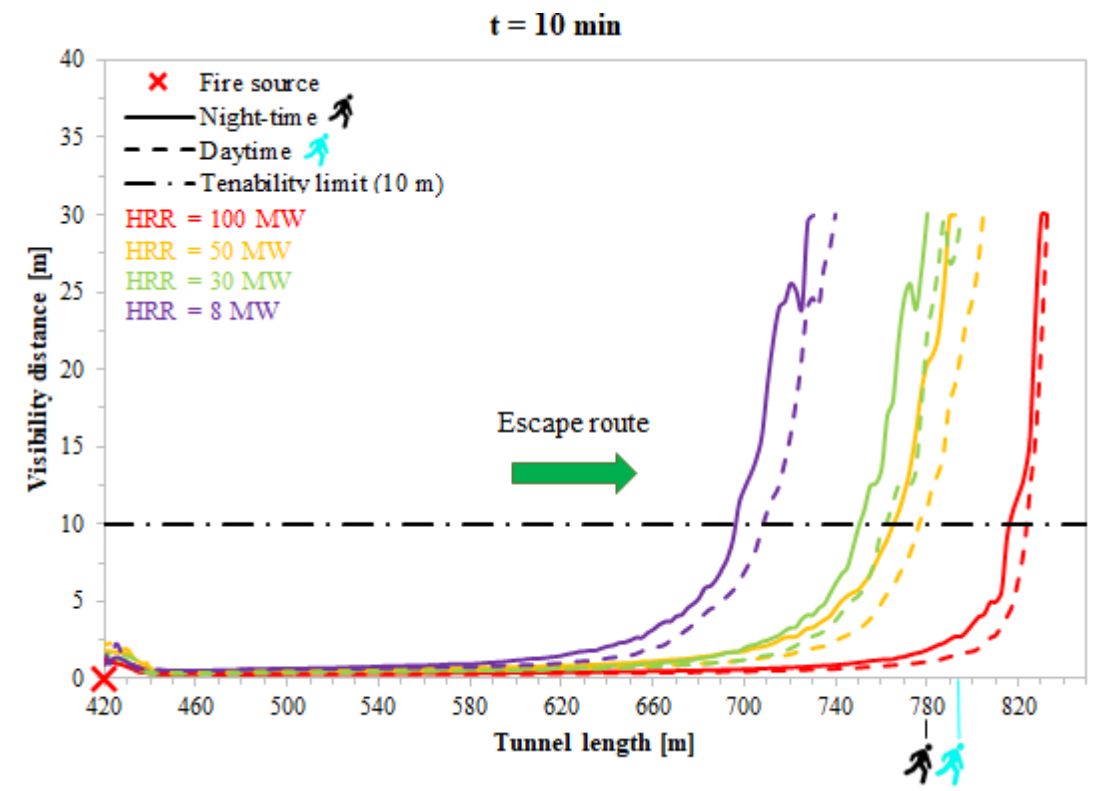

Figure 5. Longitudinal visibility distance profiles, downstream of the fire, in the bi-directional tube at both night and day after $10 \mathrm{~min}$ from the fire start, and at a height of $2 \mathrm{~m}$ along the escape route when the burning vehicle is in the middle of the tube length. 


\subsubsection{Toxic Gases}

Figures 6 and 7 show, respectively, the longitudinal profiles, downstream of the fire, of $\mathrm{CO}$ and $\mathrm{CO}_{2}$ concentration in the bi-directional tube at both night and day after $10 \mathrm{~min}$ from the fire start, and at a height of $2 \mathrm{~m}$ along the escape route.

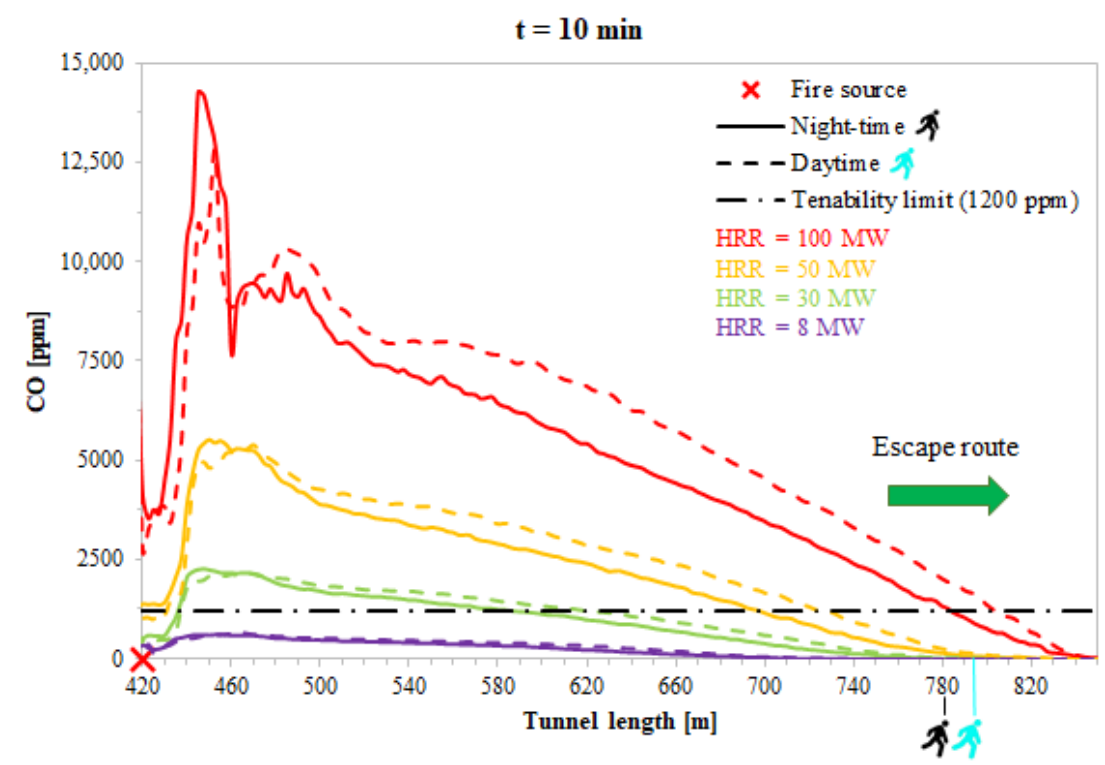

Figure 6. Longitudinal CO concentration profiles, downstream of the fire, in the bi-directional tube at both night and day after $10 \mathrm{~min}$ from the fire start, and at a height of $2 \mathrm{~m}$ along the escape route when the burning vehicle is in the middle of the tube length.

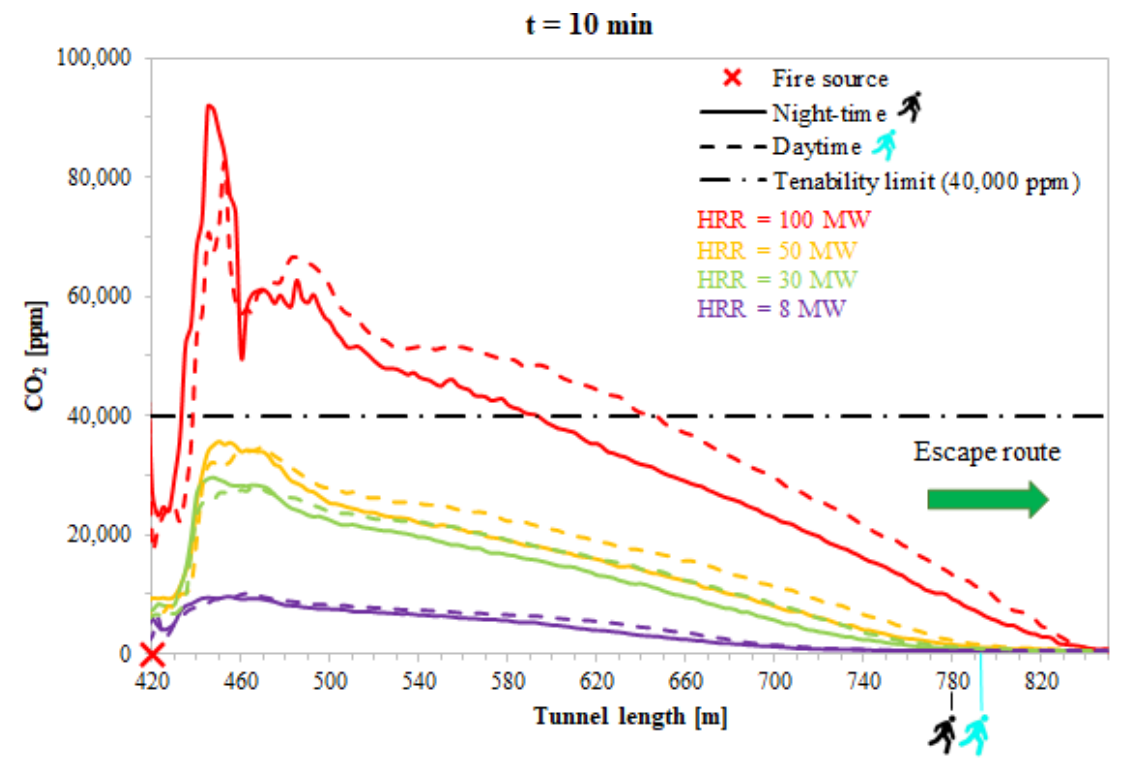

Figure 7. Longitudinal $\mathrm{CO}_{2}$ concentration profiles, downstream of the fire, in the bi-directional tube at both night and day after $10 \mathrm{~min}$ from the fire start, and at a height of $2 \mathrm{~m}$ along the escape route when the burning vehicle is in the middle of the tube length.

Figures 6 and 7 show that the $\mathrm{CO}$ and $\mathrm{CO}_{2}$ concentration are higher during the day than at night. According to Figure 6, the $\mathrm{CO}$ concentration, for the last escaping user, is less than $1200 \mathrm{ppm}$ (i.e., the tenability limit in accordance with CFPA [24]) in the case of 8,30 , and $50 \mathrm{MW}$ fires at both night and day. In the event of $100 \mathrm{MW}$ fire, when the last user is at a distance of $70 \mathrm{~m}$ and $58 \mathrm{~m}$ from portal B at night and day, respectively, the $\mathrm{CO}$ concentration is, instead, a bit higher than $1200 \mathrm{ppm}$. From Figure 7, one can see, 
instead, that the last escaping user is always exposed during his evacuation process to a $\mathrm{CO}_{2}$ concentration lower than the tenability limit of 40,000 ppm [24].

It is to be mentioned that similar environmental conditions were also found at the remaining positions occupied by the burning vehicle in the tube when used for bidirectional traffic. In order to save space, however, the results of these simulations are not reported.

The results above found show the positive effects on environmental conditions along the evacuation path in the event of fire whether the tunnel tube is used for bi-directional traffic overnight rather than daytime, when the adjacent tube is closed for maintenance, repair, and/or rehabilitation activities. However, in the case of $100 \mathrm{MW}$ fire, when the last escaping user is in the proximity of the portal $\mathrm{B}$, the visibility distance may also be less than $10 \mathrm{~m}$, and the $\mathrm{CO}$ concentration may be a bit higher than $1200 \mathrm{ppm}$. Therefore, in these circumstances it would be necessary to foresee measures capable of keeping the concentration of smoke below the mentioned threshold values. Alternatively, the presence of rescue teams stationed at the two extremities of the twin tube tunnel would be required to provide, in addition to traffic control, emergency services-operating $8 \mathrm{~h}$ a day (i.e., overnight) and five days a week (if the closure of the adjacent tube is scheduled for five weekdays a week) - and with an access time to the tube used for bi-directional traffic of less than $10 \mathrm{~min}$.

\subsubsection{Contour of Smoke Propagation}

Figure 8 shows the smoke propagation along the tunnel tube used for bi-directional traffic, for the different fire sources $(8,30,50$, and $100 \mathrm{MW})$, at both night and day when the burning vehicle is in the middle of the tube length, and after $10 \mathrm{~min}$ from the fire start.

One can see that: (i) the smoke layering length is not symmetrical in the two directions downstream and upstream of the fire because the natural ventilation pushes the smoke towards portal B, which explains the worst environmental conditions downstream of the fire; (ii) by increasing the HRR the smoke layering length increases; (iii) the smoke layering length is at night shorter than at day for HRR of 8, 30, and $50 \mathrm{MW}$, while it is the same for a HRR of $100 \mathrm{MW}$. This graphically confirms, under the aspect of smoke layering, that better environmental conditions are found at night compared with the day, except for the HRR of $100 \mathrm{MW}$ for which more or less similar results are found.

\subsubsection{Extension of the Study}

Generally speaking, it is to be said that the distance between the vehicles stopped in a queue might be also minor than the value of $10 \mathrm{~m}$ assumed overnight. Certain references of literature, for example [25], reports that the mean distance between vehicles in the queue might be up to $3 \mathrm{~m}$ (with a maximum distance of $7.5 \mathrm{~m}$ ). However, it is to be said that these studies are related to open roads, and in the event of a traffic disruption that is not due to a fire. This is different from our case in which we are studying the road tunnels in the event of a fire. When a fire occurs in a tunnel, certain warning systems are generally activated (e.g., the red light of traffic signals at the entrance portal, the variable message signs to inform tunnel users of fire, the radio-communications of the emergency, etc.) so that the driving behavior of tunnel users can be different from that on open roads. This plays a crucial role in how the vehicles form a queue and the distance between them. The drivers will become much more aware of the emergency in tunnel, and as a result major distance between the vehicles in the queue might also be expected. Bosco et al. [26], for example, showed that the distance between cars stopped follows a Gaussian distribution with mean equal to $8.91 \mathrm{~m}$ and standard deviation of $3.11 \mathrm{~m}$. Borghetti et al. [27] defined a linear dependence between the Annual Average Daily Traffic (AADT) and the distance (d) between vehicles stopped in the queue; in particular, for $\mathrm{AADT}=22,000$ vehicles $/$ day the distance between vehicles in the queue is $1 \mathrm{~m}$, while it is $10 \mathrm{~m}$ for $\mathrm{AADT}=4000$ vehicles/day. 
(a)

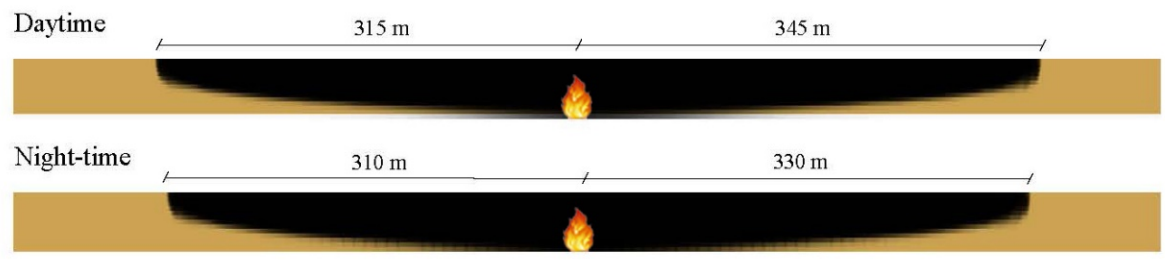

(b)

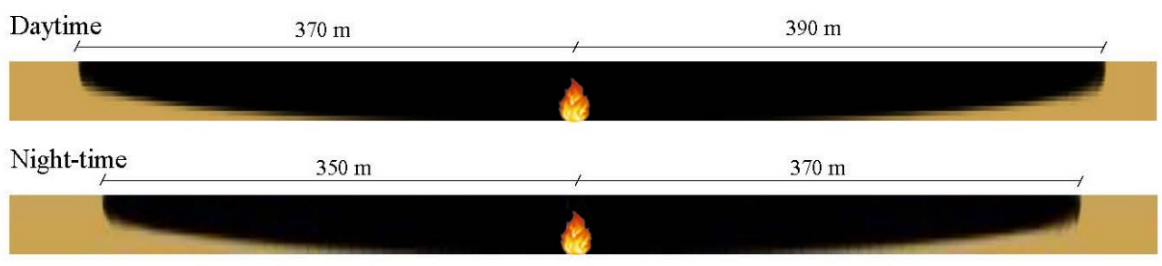

(c)

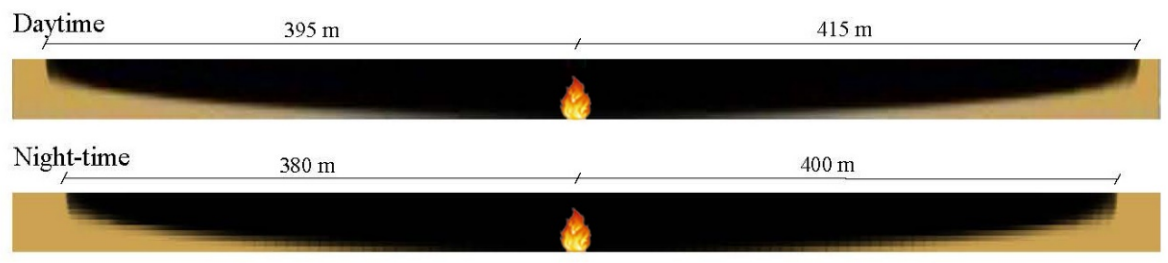

(d)

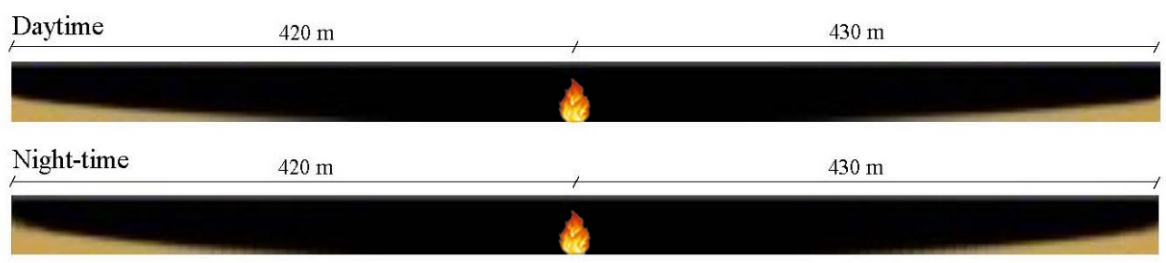

Portal A

Portal B

Figure 8. Smoke propagation in the tube used for bi-directional traffic at both night and day, after $10 \mathrm{~min}$ from the fire start, when the burning vehicle is in the middle of the tube length and for HRR of: (a) $8 \mathrm{MW}$, (b) $30 \mathrm{MW}$, (c) $50 \mathrm{MW}$, (d) $100 \mathrm{MW}$.

Therefore, contrasting results might be found in the literature. However, we have made an extension of our study by considering also a distance of $3 \mathrm{~m}$ between the vehicles stopped in the queue overnight. In addition, we have assumed a minor arrival time (2.25 s) of the first vehicle upstream of the burning vehicle (i.e., equal to that of the day).

Figure 9 shows the longitudinal profiles of temperature, radiant heat flux, visibility distance, $\mathrm{CO}$ and $\mathrm{CO}_{2}$ concentrations, downstream of the fire, in the bi-directional tube for both $\mathrm{d}=3 \mathrm{~m}$ (overnight) and $\mathrm{d}=1 \mathrm{~m}$ (peak-hours) after $10 \mathrm{~min}$ from the fire start, and at a height of $2 \mathrm{~m}$ along the escape route when the burning vehicle is in the middle of the tube length. Figure 9 confirms the results already found in the previous paragraphs, namely that safety issues might arise only in the event of $100 \mathrm{MW}$ fire both during night and day, due to the reduced visibility and the high $\mathrm{CO}$ concentration.

As it is also expected, the longitudinal profiles of the fire-induced threats during the night, by assuming a distance between the vehicles in the queue equal to $3 \mathrm{~m}$, are closer to those of the day $(\mathrm{d}=1 \mathrm{~m})$ if compared to the case in which $\mathrm{d}=10 \mathrm{~m}$. This is due to the greater number of vehicles stopped in the proximity of the burning vehicle. 

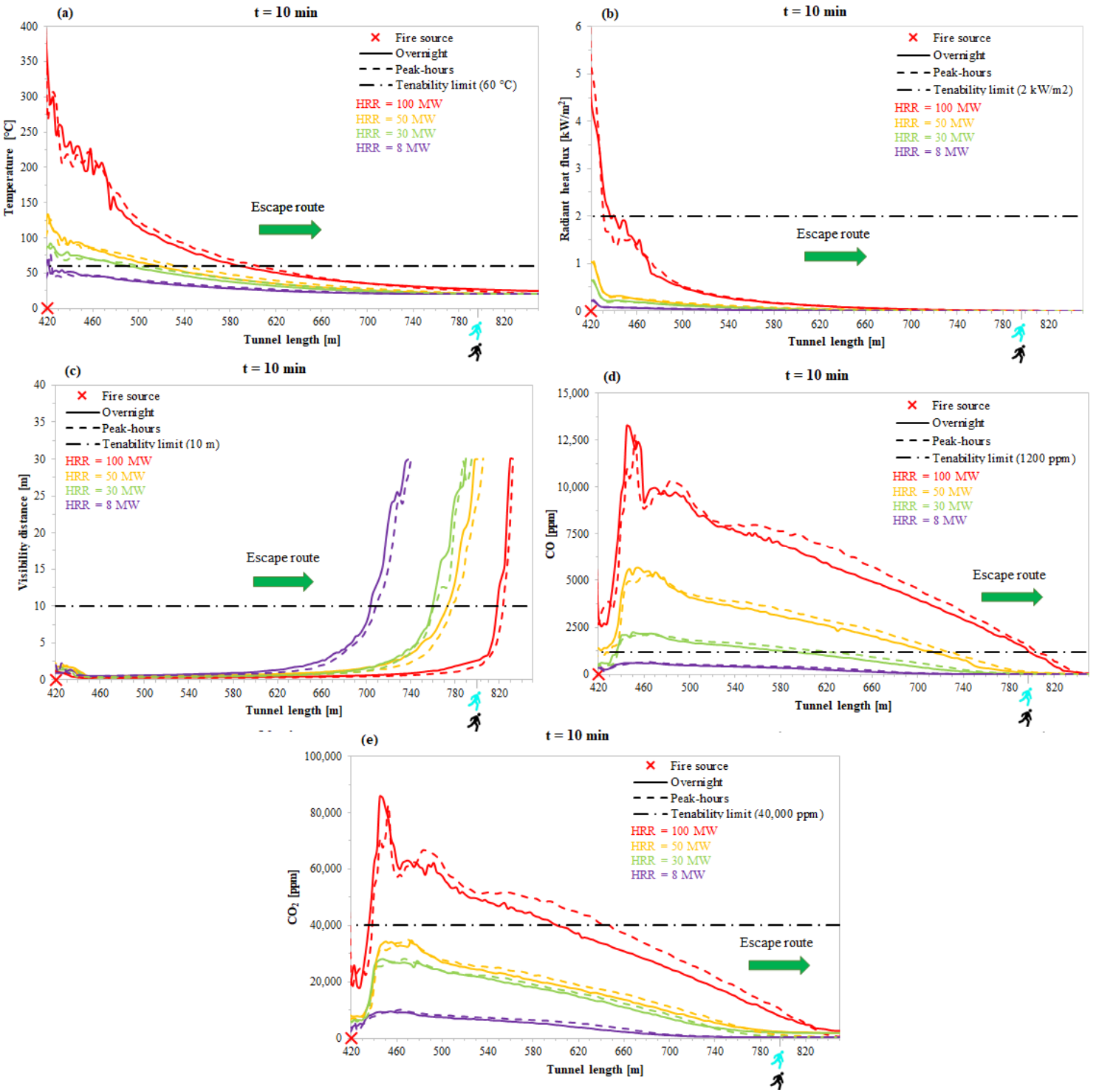

Figure 9. Longitudinal profiles of: (a) Temperature; (b) Radiant heat flux; (c) Visibility distance; (d) CO concentration; (e) $\mathrm{CO}_{2}$ concentration, downstream of the fire, in the bi-directional tube for both $\mathrm{d}=3 \mathrm{~m}$ (overnight) and $\mathrm{d}=1 \mathrm{~m}$ (peak-hours) after $10 \mathrm{~min}$ from the fire start, and at a height of $2 \mathrm{~m}$ along the escape route when the burning vehicle is in the middle of the tube length.

\section{Quantitative Risk Analysis}

\subsection{Methodology}

Although the results of the FDS+Evac have shown certain benefits on environmental conditions along the evacuation route in the event of fire when the tube is used for bi-directional traffic at night rather than during the day, the consequences in terms of the probability (or cumulative frequency) of potential fatalities have not yet been quantified. There are several methods for doing this. However, a Quantitative Risk Analysis (QRA) based on a probabilistic approach is generally implemented. The probabilistic approach includes the following main steps: selection of target, identification of tunnel system, definition of hazards, determination of the probability (or frequency) of occurrence of each hazard, evaluation of consequences, and quantification of the risk as the sum of probabilities multiplied by consequences. This involves event tree, fault tree, and consequences estimation models. Societal risk (i.e., the expected potential number of fatalities in a tunnel per years) is, in general, the main output of a QRA. It is often expressed in terms of F-N curves, in which $\mathrm{F}$ is the cumulative frequency that the number of fatalities is $\geq \mathrm{N}$. 
The F-N curves computed for a specific tunnel might be used, for example, to show the efficiency of the implementation of safety measures; or one might compare the F-N curves of a same tube used under different vehicular traffic directions, as in our case, in order to make a comparison between the risk levels. In particular, a risk analysis is required by the European Directive 2004/54/EC [4], as well as by the Italian Ministry of Infrastructure and Transports [28], when a tunnel (belonging to the Trans-European Road Network, and with $\mathrm{L} \geq 500 \mathrm{~m}$ ) is opened up to the transit of dangerous goods. Specific applications of the quantitative risk analysis can be found in Caliendo and De Guglielmo [29-32], and Caliendo and Genovese [33].

\subsection{Event Tree}

The definition of hazard (i.e., fire of 8, 30, 50, or $100 \mathrm{MW}$ ), as well as the determination of its probability of occurrence, comes from the event tree. It is to be remembered that the event tree is a graphical representation used to draw different chronological series of subsequent events by starting from an initial event. In the event tree is defined the probability $(\mathrm{P})$ of occurrence of each intermediate event once that is given the probability of the initial event. In our study, we used the event tree reported in ANAS [34]. In this respect, the initial event is represented by the annual frequency of traffic accidents in road tunnels, which is then assumed to be followed by three types of events: traffic collisions $(p=94.9 \%)$, fires $(p=5 \%)$, and releases of dangerous goods $(p=0.1 \%)$; fires are subsequently assumed to involve two different types of vehicles: light vehicles $(p=70 \%)$ or heavy vehicles $(p=30 \%)$; for each of the two mentioned types of vehicles, the fire is considered to be non-relevant ( $p=30 \%$ for light vehicle, or $p=80 \%$ for heavy vehicles) or relevant ( $p=70 \%$ for light vehicles, or $p=20 \%$ for heavy vehicles); finally relevant fires of light vehicles might involve a HRR of $8 \mathrm{MW}(p=2.5 \%)$, while relevant fires of heavy vehicles might involve a HRR of $30(p=14.5 \%), 50(p=2.5 \%)$ and $100 \mathrm{MW}(p=1.5 \%)$.

\subsection{Annual Frequency of Traffic Accidents}

Regarding the initial event of traffic accidents, first of all, we assumed certain average accident rates, according to the literature [35], equal to 0.34 accidents $/ 10^{6}$ vehicles $\cdot \mathrm{km}$ and 0.42 accidents $/ 10^{6}$ vehicles $\cdot \mathrm{km}$ for the day and the night in the tunnel tube, respectively. In order to estimate the annual frequency of traffic accidents, it was necessary to take into account the fact that we had considered 6 hours of peak-traffic volumes during the day (i.e., with 3200 vehicles/hour for the two lanes) and $8 \mathrm{~h}$ of lower hourly traffic volumes during the night (i.e., with 400 vehicles/hour for the two lanes). These hourly traffic volumes were modified in the corresponding Equivalent Annual Average Daily Traffic (EAADT) of 19,200 vehicles/day and 3200 vehicles/day for the day and the night, respectively. By using the aforementioned both traffic accident rates and EAADTs, we computed the annual frequency of traffic accidents, which were found to be equal to 2.025 and 0.417 (traffic accidents/year) with reference respectively to the day and the night in the tube.

\subsection{Annual Fire Frequency}

The annual frequency of each fire (i.e., HRR of $8,30,50$, or $100 \mathrm{MW}$ ) was computed by multiplying the aforementioned annual frequency of traffic accidents (related to the day or the night) by the corresponding both intermediate and final probabilities of each event contained in the mentioned event tree (i.e., with reference to the $100 \mathrm{MW}$ and at night, we computed: $0.417 \times 0.05 \times 0.3 \times 0.2 \times 0.015=1.88 \times 10^{-5}$ ). Table 2 shows all the results obtained.

The probability of the occurrence of a given fire in one of the five longitudinal positions of fire within the investigated tube for bi-directional traffic (i.e., 145, 280, 420, 570, and $710 \mathrm{~m}$ from portal A) was assumed to be always the same and equal to 0.2. Consequently, we computed the annual frequency of the occurrence of fire in each of the mentioned positions by multiplying the values of Table 2 by 0.2 . 
Table 2. Annual frequency of the occurrence of fire scenarios.

\begin{tabular}{ccc}
\hline \multirow{2}{*}{$\begin{array}{c}\text { Fire } \\
\text { Scenario }\end{array}$} & \multicolumn{2}{c}{ Annual Frequency of the Occurrence of Fire Scenarios [1/Year] } \\
\cline { 2 - 3 } & Day & Night \\
\hline $8 \mathrm{MW}$ & $1.24 \times 10^{-3}$ & $2.55 \times 10^{-4}$ \\
$30 \mathrm{MW}$ & $8.01 \times 10^{-4}$ & $1.81 \times 10^{-4}$ \\
$50 \mathrm{MW}$ & $1.52 \times 10^{-4}$ & $3.13 \times 10^{-5}$ \\
$100 \mathrm{MW}$ & $9.11 \times 10^{-5}$ & $1.88 \times 10^{-5}$ \\
\hline
\end{tabular}

\subsection{F-N Curves}

The results of the FDS+Evac in terms of the exposure of evacuating users (downstream of the fire in the direction of portal B) to toxic gases expressed by means of the FED toxic gases as well as the exposure to heat expressed by the FED heat according to DiNenno et al. [22], were used for understanding when the tenability limits were exceeded (i.e., FED toxic gases $\geq 1$, and/or FED heat $\geq 1$ (for a greater in-depth knowledge see Caliendo et al. [18])). In this respect, it is to be stressed that the risk analysis was carried out taking into account both the FEDs (i.e., FED toxic gases and FED heat) of all tunnel users and their complete evacuation process (i.e., between $t=0$ and $t=10$ min after the fire start). This was made for each type of fire (i.e., HRR of $8,30,50$, and $100 \mathrm{MW}$ ) and for the five different positions of fire in the tunnel tube used for bi-directional traffic (i.e., 145, 280, 420, 570, and $710 \mathrm{~m}$ from portal A). We found that for some combinations of HRR and positions of fire, the FED toxic gases might be more than 1 , while the FED heat was always $<<1$. As a result, we estimated the number of potential fatalities that might be caused by the exposure to toxic gases for the mentioned combinations of HRR and fire positions.

The number of potential fatalities, related to each fire and position, was then associated to the corresponding annual frequency of fire. Subsequently, we calculated the individual cumulative frequency of each fire, and by combining the individual cumulative frequency, we computed the final cumulative frequency F-N with reference to the escaping users downstream of the fire from the tube used for bi-directional traffic. Figure 10 shows, in a bi-logarithmic diagram, the relationship between the final cumulative frequency $(\mathrm{F})$ and the potential number of fatalities $(\mathrm{N})$ of the tube used for bi-directional traffic at both night and day. In this regard, it is to be stressed that overnight the distance (d) between the vehicles in the queue was assumed to be equal both to $10 \mathrm{~m}$ and $3 \mathrm{~m}$. In the latter case, as well as during the day, the first vehicle is assumed to stop in front of the burning vehicle after $2.25 \mathrm{~s}$. Figure 10 confirms graphically that the F-N curves with reference to the night cases lies always below that of the day.

Table 3 quantifies the reduction of the risk levels by comparing the annual cumulative frequencies for a given number of potential fatalities during the day and the night. In brackets are reported the values of the annual cumulative frequency, as well as the reduction of the risk level, when the distance between the vehicles stopped in the queue is 3 m overnight. In particular, it shows that: (i) the cumulative frequencies of having a certain number of potential fatalities during the night is much lower than the day (e.g., $\mathrm{F}=3.86 \times 10^{-5}$ for $\mathrm{N}=1$ potential fatality at night (with $\mathrm{d}=10 \mathrm{~m}$ ), or $\mathrm{F}=3.86 \times 10^{-5}$ at night (with $\mathrm{d}=3 \mathrm{~m}$ ), against $\mathrm{F}=1.88 \times 10^{-4}$ associated to the day); (ii) the maximum number of potential fatalities that might be expected during the night due the exposure to toxic gases is also much lower ( 25 when $\mathrm{d}=10 \mathrm{~m}$ and 35 when $\mathrm{d}=3 \mathrm{~m}$ during night-time against 65 during daytime); (iii) the reduction of the risk level (for $\mathrm{N} \leq 25$ and $\mathrm{N} \leq 35$ potential fatalities when $d=10 \mathrm{~m}$ and $3 \mathrm{~m}$, respectively) is between 80 and $100 \%$.

Therefore, significant advantages for escaping users (downstream of the fire in direction of portal B) are expected if the investigated tunnel tube is used for bi-directional traffic during the night rather than the day.

It is to be stressed that the results of this paper are related to a distance between the vehicles stopped within the road tunnel tube in event of a fire (during the night) equal both to 3 and $10 \mathrm{~m}$, as well as for the arrival time of the first vehicle downstream of the 
fire source equal both to 2.25 and $18 \mathrm{~s}$. Therefore, most of possible cases are expected to be contained in the ranges investigated in the present paper.

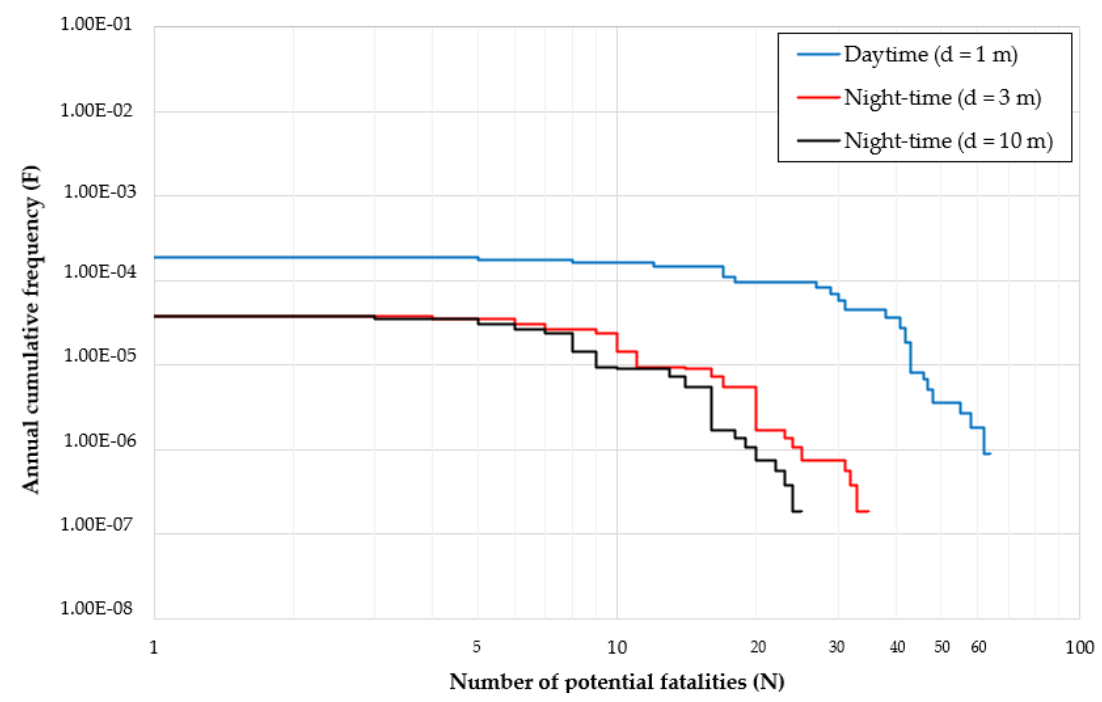

Figure 10. F-N curves related to escaping users (downstream of the fire in direction of the portal B) of the investigated tunnel tube, when is used for bi-directional traffic, during the day and the night, respectively; with d equal to the distance between the vehicles in the queue.

Table 3. Risk level of escaping users (downstream of the fire in direction of portal B) in the investigated one-way tube when used for bi-directional traffic. In brackets are reported the values of the annual cumulative frequency, as well as the reduction of the risk level, when $\mathrm{d}=3 \mathrm{~m}$.

\begin{tabular}{cccc}
\hline \multirow{2}{*}{$\begin{array}{c}\text { Number of Potential } \\
\text { Fatalities (N) }\end{array}$} & \multicolumn{2}{c}{ Annual Cumulative Frequency (F) } & \multirow{2}{*}{$\begin{array}{c}\text { Reduction } \\
\text { of the Risk Level }\end{array}$} \\
\cline { 2 - 3 } & Day & Night & $80 \%(80 \%)$ \\
5 & $1.88 \times 10^{-4}$ & $3.86 \times 10^{-5}\left(3.86 \times 10^{-5}\right)$ & $83 \%(81 \%)$ \\
10 & $1.75 \times 10^{-4}$ & $3.07 \times 10^{-5}\left(3.41 \times 10^{-5}\right)$ & $94 \%(92 \%)$ \\
15 & $1.65 \times 10^{-4}$ & $9.26 \times 10^{-6}\left(1.46 \times 10^{-5}\right)$ & $96 \%(94 \%)$ \\
20 & $1.48 \times 10^{-4}$ & $5.63 \times 10^{-6}\left(9.26 \times 10^{-6}\right)$ & $99 \%(98 \%)$ \\
25 & $9.56 \times 10^{-5}$ & $7.51 \times 10^{-7}\left(1.69 \times 10^{-6}\right)$ & $100 \%(99 \%)$ \\
30 & $9.47 \times 10^{-5}$ & $1.88 \times 10^{-7}\left(7.51 \times 10^{-7}\right)$ & $-(99 \%)$ \\
35 & $5.75 \times 10^{-5}$ & Not applicable $\left(7.51 \times 10^{-7}\right)$ & $-(100 \%)$ \\
40 & $5.51 \times 10^{-5}$ & Not applicable $\left(1.88 \times 10^{-7}\right)$ & - \\
50 & $3.63 \times 10^{-5}$ & Not applicable & - \\
60 & $3.65 \times 10^{-6}$ & Not applicable & - \\
65 & $1.82 \times 10^{-6}$ & Not applicable & - \\
\hline
\end{tabular}

\subsection{Research Findings}

With reference to the research findings of our work, it is to be said that in general a comparison is very difficult with other studies of the literature for different modeling and parameters implemented, human behavior of users during the evacuation process, different safety countermeasures and control systems. Full-scale experiments on the other hand are more useful, but they are often expensive and/or dangerous and require the disruption of the traffic flow through the tunnel with the use of alternative itineraries on open roads. However, it is to be stressed that the authors of the present paper preliminary validated the FDS code by means of a comparison with the experimental data reported in Xue et al. [21]. Therefore, the authors are confident that by carrying out numerical simulations based on an appropriate fluid-dynamic analysis, as well as by using a suitable probabilistic approach for individualizing the F-N curves, they have calibrated and applied the modeling process quite accurately, so that the research results can provide an interesting contribution to 
the state-of-the-art by showing the effects of hourly traffic volumes on the risk level of tunnel users in the event of fire. However, future research might be also focused on the uncertainties analysis for making a more consolidated verify of the findings obtained.

\section{Summary, Conclusions and Discussion for Future Investigations}

The main reasons for justifying the present paper were the need to develop a fluid dynamic modeling capable of reproducing different fire scenarios occurring in a one-way tunnel tube with natural ventilation, used for bi-directional traffic when the adjacent tube is closed for maintenance, repair, or rehabilitation activities; and for assessing the differences in the risk levels to which users are exposed during their evacuation process during the night and the day.

To do so, the Fire Dynamics Simulator (FDS) and its evacuation module Evac were used; and the results of simulations were implemented for performing a Quantitative Risk Analysis (QRA) based on a probabilistic approach for evaluation the societal risk expressed in terms of F-N curves.

Specifically, four types of fires involving two cars, a bus, and two different types of HGVs were investigated (i.e., characterized by HRR of 8, 30, 50, and $100 \mathrm{MW}$, respectively). Each fire source was positioned in five different longitudinal locations in the tube (i.e., 145, 280, 420, 570, and $710 \mathrm{~m}$ from portal A).

The evacuation process in the event of fire within the tube used for bi-directional traffic, due to the direction of the natural ventilation (from portal A to B), was worse for escaping users downstream of the fire in the direction of emergency exit and/or portal B. However, the results showed the positive effects on environmental conditions (in terms of temperature, visibility distance, $\mathrm{CO}$ and $\mathrm{CO}_{2}$ concentration) along the evacuation path when the tunnel tube was used for bi-directional traffic during the night rather than the day (which was justified by lower night traffic volumes). Only for the case of $100 \mathrm{MW}$ fire, the last escaping user was found to be interested by a visibility distance less than $10 \mathrm{~m}$, and a CO concentration higher than $1200 \mathrm{ppm}$, in the proximity of the portal B. In these circumstances, measures capable of keeping the concentration of smoke below the threshold values should be implemented; alternatively, the presence of rescue teams equipped with emergency services, and with an access time within the tube of less than $10 \mathrm{~min}$, should be foreseen.

The results of the quantitative risk analysis, however, showed that: (i) the F-N curve of the tube used for bi-directional traffic with reference to the night always lies below that of the day, (ii) the cumulative frequencies of having a certain number of potential fatalities due to toxic gases during the night is much lower than the day; (iii) the maximum number of potential fatalities during the night is much lower; (iv) the reduction in the risk level is between 80 and $100 \%$ for bi-directional night traffic compared to the daytime one.

It is to be mentioned that if the closure of the adjacent tube is not scheduled, but is caused suddenly by an incident (e.g., traffic accident or fire), for the use of the tube interested by bi-directional traffic the presence of rescue teams stationed at the two extremities of the twin tube tunnel is recommended for the period of emergency time.

Although the results have shown certain benefits on environmental conditions along the evacuation path in the event of fire, when the tunnel tube is used for bi-directional traffic during the night rather than the day, there are still some points worth investigating. For example, the risk level of using an alternative open road when a tube is closed for given activities should also be evaluated.

Another important field of future research might be to assess the risk level due to the transit of alternative vehicles, such as the Electric Vehicles (EVs), through tunnels. The battery of EVs might be accompanied by significant releases of toxic gases, in the event of fire, and cause severe negative consequences due to closed spaces.

Low flammability road pavements might also be a topic of interest for research in order to limit the emission of toxic substances in tunnels due to burning pavement materials in the event of fire. Traditional pavements (e.g., in cement concrete or asphalt mixtures), 
the behavior of which under ordinary conditions of traffic might be seen, for example, in Caliendo and Parisi [36] and Caliendo [37], do not appear to be sufficiently suitable also for the scope mentioned. Therefore, innovative materials should be employed in tunnel pavements, which should be inert to combustion process.

Finally, given the essential role of tunnels within a transportation network in supporting the mobility of goods and people, and providing response in emergency circumstances, the resilience of road tunnels (i.e., the ability of the system to maintain its service level or to bring itself back to that level in a determined time) should also be investigated. In this respect, traffic simulation tools might be more especially used. Certain applications of these tools can also be found, for example, in Caliendo and Guida [38], Caliendo and De Guglielmo [39], Caliendo [40], Astarita et al. [41], and Caliendo et al. [42]. However, these studies, as well as those of other authors based on traffic simulation tools, should be extended to the transport networks containing road tunnels in order to be concatenated to the concept of resilience.

The lack of knowledge on the aforementioned topics needs redressing by future studies in the field of tunnel safety engineering.

Author Contributions: Conceptualization, C.C., G.G., and I.R.; methodology, C.C., G.G., and I.R.; software, C.C., G.G., and I.R.; validation, C.C., G.G., and I.R.; formal analysis, C.C., G.G., and I.R.; investigation, C.C., G.G., and I.R.; data curation, C.C., G.G., and I.R.; writing-original draft preparation, C.C., G.G., and I.R.; writing-review and editing, C.C., G.G., and I.R.; visualization, C.C., G.G., and I.R.; supervision, C.C. All authors have read and agreed to the published version of the manuscript.

Funding: This research received no external funding.

Institutional Review Board Statement: Not applicable.

Informed Consent Statement: Informed consent was obtained from all subjects involved in the study.

Data Availability Statement: The data presented in this study are available on request from the corresponding author. The data are not publicly available due to privacy restrictions.

Conflicts of Interest: The authors declare no conflict of interest.

\section{Nomenclature}

\begin{tabular}{|c|c|c|}
\hline Symbol & Unit & Description \\
\hline AADT & vehicles/day & Annual Average Daily Traffic \\
\hline CFD & & Computational Fluid Dynamics \\
\hline $\mathrm{d}$ & $\mathrm{m}$ & Distance between the vehicles in the queue \\
\hline EAADT & vehicles/day & Equivalent Annual Average Daily Traffic \\
\hline EVs & & Electric Vehicles \\
\hline $\mathrm{F}$ & 1/year & Annual cumulative frequency \\
\hline HGV & & Heavy Good Vehicle \\
\hline HRR & MW & Heat Release Rate \\
\hline $\mathrm{L}$ & $\mathrm{m}$ & Tunnel length \\
\hline $\mathrm{N}$ & & Number of potential fatalities \\
\hline $\mathrm{P}$ & $\%$ & Probability \\
\hline QRA & & Quantitative Risk Analysis \\
\hline $\mathrm{t}$ & $\min$ & Time \\
\hline VHP & vehicles $/ \mathrm{h}$ & Peak hour of traffic volume \\
\hline \multicolumn{3}{|l|}{ Sup and subscripts } \\
\hline $\mathrm{CO}$ & & Carbon monoxide \\
\hline $\mathrm{CO}_{2}$ & & Carbon dioxide \\
\hline FED $_{\text {heat }}$ & & Fractional Effective Dose due to heat exposure \\
\hline FED toxic gases & & Fractional Effective Dose due to toxic gases exposure \\
\hline
\end{tabular}




\section{References}

1. McGrattan, K.; Hostikka, S.; Floyd, J.; McDermott, R.; Vanella, M. Fire Dynamics Simulator: User's Guide, 6th ed.; National Institute of Standards and Technology, Fire Research Division, Engineering Laboratory: Gaithersburg, MD, USA, 2019.

2. McGrattan, K.; Hostikka, S.; Floyd, J.; McDermott, R.; Vanella, M. Fire Dynamics Simulator: Technical Reference Guide, 6th ed.; National Institute of Standards and Technology, Fire Research Division, Engineering Laboratory: Gaithersburg, MD, USA, 2019

3. Korhonen, T. Fire Dynamic Simulator with Evacuation: FDS+Evac Technical Reference and User's Guide; VTT Technical Research Centre of Finland: Espoo, Finland, 2018.

4. European Parliament and Council. Directive 2004/54/EC. In Official Journal of the European Union. L.167; European Parliament and Council: Bruxelles, Belgium, 2004.

5. Modic, J. Fire simulation in road tunnels. Tunn. Undergr. Space Technol. 2003, 18, 525-530. [CrossRef]

6. Li, J.S.M.; Chow, W.K. Numerical studies on performance evaluation of tunnel ventilation safety systems. Tunn. Undergr. Space Technol. 2003, 18, 435-452. [CrossRef]

7. Hu, L.H.; Huo, R.; Wang, H.B.; Yang, R.X. Experimental and Numerical Studies on Longitudinal Smoke Temperature Distribution Upstream and Downstream from the Fire in a Road Tunnel. J. Fire Sci. 2007, 25, 23-43. [CrossRef]

8. Bari, S.; Naser, J. Simulation of smoke from a burning vehicle and pollution levels caused by traffic jam in a road tunnel. Tunn. Undergr. Space Technol. 2005, 20, 281-290. [CrossRef]

9. Yang, G.S.; Peng, L.M.; Zhang, J.H.; An, Y. Simulation of people's evacuation in tunnel fire. J. Cent. South Univ. Technol. 2006, 13, 307-312. [CrossRef]

10. Betta, V.; Cascetta, F.; Musto, M.; Rotondo, G. Fluid dynamic performances of traditional and alternative jet fans in tunnel longitudinal ventilation systems. Tunn. Undergr. Space Technol. 2010, 25, 415-422. [CrossRef]

11. Babapoor, A.; Bab, V.; Sabegh, M.A. Simulation of a Tunnel Fire by CFD Technique. In Proceedings of the 3rd National Conference on Modern Researches in Chemistry and Chemical Engineering, Mahshahr, Iran, 15 December 2011.

12. Caliendo, C.; Ciambelli, P.; De Guglielmo, M.L.; Meo, M.G.; Russo, P. Numerical simulation of different HGV fire scenarios in curved bi-directional road tunnels and safety evaluation. Tunn. Undergr. Space Technol. 2012, 31, 33-50. [CrossRef]

13. Caliendo, C.; Ciambelli, P.; De Guglielmo, M.L.; Meo, M.G.; Russo, P. Simulation of People Evacuation in the Event of a Road Tunnel Fire. Procedia Soc. Behav. Sci. 2012, 53, 178-188. [CrossRef]

14. Caliendo, C.; Ciambelli, P.; De Guglielmo, M.L.; Meo, M.G.; Russo, P. Simulation of fire scenarios due to different vehicle types with and without traffic in a bi-directional road tunnel. Tunn. Undergr. Space Technol. 2013, 37, 22-36. [CrossRef]

15. Lin, P.; Zhang, Y.; Li, T.; Si, Y. A Numerical Study on the Impact of Vehicles' Blockage on the Performance of Semi-transversal Smoke Control System in Tunnel Fire. Procedia Eng. 2016, 135, 247-259. [CrossRef]

16. Caliendo, C.; Ciambelli, P.; De Guglielmo, M.L.; Meo, M.G.; Russo, P. Computational analysis of fire and people evacuation for different positions of burning vehicles in a road tunnel with emergency exits. Cogent Eng. 2018, 5, 1530834. [CrossRef]

17. Truchot, B.; Willmann, C.; Guivarch, J. People evacuation in tunnel fires: A cross evaluation of two methodologies. J. Phys. Conf. Ser. 2018, 1107, 072004. [CrossRef]

18. Caliendo, C.; Genovese, G.; Russo, I. Risk Analysis of Road Tunnels: A Computational Fluid Dynamic Model for Assessing the Effects of Natural Ventilation. Appl. Sci. 2021, 11, 32. [CrossRef]

19. Król, A.; Król, M. Numerical investigation on fire accident and evacuation in a urban tunnel for different traffic conditions. Tunn. Undergr. Space Technol. 2021, 109, 103751. [CrossRef]

20. Schrefler, B.A.; Brunello, P.; Gawin, D.; Majorana, C.E.; Pesavento, F. Concrete at high temperature with application to tunnel fire. Comput. Mech. 2002, 29, 43-51. [CrossRef]

21. Xue, H.; Ho, J.C.; Cheng, Y.M. Comparison of different combustion models in enclosure fire simulation. Fire Saf. J. 2001, 36, 37-54. [CrossRef]

22. DiNenno, P.J.; Drysdale, D.; Beyler, C.L.; Douglas Walton, W.; Custer, R.L.P.; Hall, J.R.; Watts, J.M. SFPE Handbook of Fire Protection Engineering, 3rd ed.; National Fire Protection Association: Quincy, MA, USA, 1995.

23. UPTUN. Workpackage 2-Fire Development and Mitigation Measures. 2008. Available online: https://iwma.net/fileadmin/ user_upload/general/uptun_guidance.pdf (accessed on 15 January 2021).

24. CFPA-E. Fire Safety Engineering Concerning Evacuation from Buildings. European Guideline CFPA-E, No.19. 2009. Available online: http:/ / www.cfpa-e.eu/wp-content/uploads/files/guidelines/CFPA_E_Guideline_No_19_2009.pdf (accessed on 15 January 2021).

25. Lu, C.; Dong, J.; Houchin, A.; Liu, C. Incorporating the standstill and time headway distributions into freeway car-following models and an application to estimating freeway travel time reliability. J. Intell. Transp. Syst. 2019, 25, 21-40. [CrossRef]

26. Bosco, D.; Lovreglio, R.; Frassoldati, A.; Derudi, M.; Borghetti, F. Queue formation and evacuation modeling in road tunnels during fires. Chem. Eng. Trans. 2018, 67, 805-810.

27. Borghetti, F.; Cerean, P.; Derudi, M.; Frassoldati, A. An Analytical Model for Risk Analysis; Springer International Publishing: Berlin/Heidelberg, Germany, 2019. [CrossRef]

28. Italian Ministry of Infrastructures and Transports. Adoption of the Directive 2004/54/EC on the Safety of Tunnels Belonging to the Trans-European Road Network; G.U., No. 235; Italian Ministry of Infrastructures and Transports: Rome, Italy, 2006.

29. Caliendo, C.; Guglielmo, M.L. Quantitative Risk Analysis based on the Impact of Traffic Flow in a Road Tunnel. Int. J. Math. Comput. Simul. 2016, 10, 39-45. 
30. Caliendo, C.; Guglielmo, M.L. Simplified method for risk evaluation in unidirectional road tunnels related to dangerous goods vehicles. Int. J. Civil Eng. Technol. 2017, 8, 960-968.

31. Caliendo, C.; De Guglielmo, M.L. Quantitative Risk Analysis on the Transport of Dangerous Goods through a Bi-Directional Road Tunnel. Risk Anal. 2017, 37, 116-129. [CrossRef] [PubMed]

32. Caliendo, C.; De Guglielmo, M.L. Risk level evaluation of dangerous goods through road tunnels. Saf. Sci. 2019, 91, 1-10.

33. Caliendo, C.; Genovese, G. Quantitative Risk Assessment on the Transport of Dangerous Goods Vehicles through Unidirectional Road Tunnels: An Evaluation of the Risk of Transporting Hydrogen. Risk Anal. 2020. [CrossRef] [PubMed]

34. ANAS. Linee Guida per la Progettazione Della Sicurezza nelle Gallerie Stradali Secondo la Normativa Vigente. Circolare n¹79431/2009. Available online: https://www.stradeanas.it/sites/default/files/pdf/Linee_guida_sicurezza_gallerie_2009.pdf (accessed on 15 January 2021).

35. Martin, J.L. Relationship between crash rate and hourly traffic flow on interurban motorways. ACC Anal. Prev. 2002, 34, 619-629. [CrossRef]

36. Caliendo, C.; Parisi, A. Stress-Prediction Model for Airport Pavements with Jointed Concrete Slabs. J. Transp. Eng. 2010, 136, 664-677. [CrossRef]

37. Caliendo, C. Local Calibration and Implementation of the Mechanistic-Empirical Pavement Design Guide for Flexible Pavement Design. J. Transp. Eng. 2012, 138, 348-360. [CrossRef]

38. Caliendo, C.; Guida, M. Microsimulation Approach for Predicting Crashes at Unsignalized Intersections Using Traffic Conflicts. J. Transp. Eng. 2012, 138, 1453-1467. [CrossRef]

39. Caliendo, C.; De Guglielmo, M.L. Road Transition Zones between the Rural and Urban Environment: Evaluation of Speed and Traffic Performance Using a Microsimulation Approach. J. Transp. Eng. 2013, 139, 295-305. [CrossRef]

40. Caliendo, C. Delay Time Model at Unsignalized Intersections. J. Transp. Eng. 2014, 140, 04014042. [CrossRef]

41. Astarita, V.; Caliendo, C.; Giofrè, V.P.; Russo, I. Surrogate Safety Measures from Traffic Simulation: Validation of Safety Indicators with Intersection Traffic Crash Data. Sustainability 2020, 12, 4974. [CrossRef]

42. Caliendo, C.; Ciambelli, P.; Del Regno, R.; Meo, M.G.; Russo, P. Modeling and numerical simulation of pedestrian flow evacuation from a multi-storey historical building in the event of fire applying safety engineering tools. J. Cult. Herit. 2020, 41, 188-199. [CrossRef] 